\title{
Students' strategies for learning identities as industrial workers in a Swedish upper secondary school VET programme
}

Lisa Ferm, Maria Gustavsson, Daniel Persson Thunqvist and Louise Svensson

The self-archived postprint version of this journal article is available at Linköping University Institutional Repository (DiVA):

http:/ / urn.kb.se/ resolve?urn=urn:nbn:se:liu:diva- 142820

N.B.: When citing this work, cite the original publication.

This is an electronic version of an article published in:

Ferm, L., Gustavsson, M., Persson Thunqvist, D., Svensson, L., (2017), Students' strategies for learning identities as industrial workers in a Swedish upper secondary school VET programme, J ournal of Vocational Education and Training, 1-19. https:/ / doi.org/ 10.1080/ 13636820.2017.1394357

Original publication available at:

https:/ / doi.org/ 10.1080/ 13636820.2017.1394357

Copyright: Taylor \& Francis (Routledge)

http:// www.routledge.com/ 


\title{
Students' strategies for learning identities as industrial workers in a Swedish upper secondary school VET programme
}

\author{
Lisa Ferm ${ }^{1}$, Daniel Persson Thunqvist ${ }^{1,2}$, Louise Svensson ${ }^{1,2}$, Maria \\ Gustavsson $^{1,2}$ \\ ${ }^{1}$ Department of Behavioural Sciences and Learning, Linköping University, Linköping, \\ Sweden
}

${ }^{2}$ HELIX Competence Centre, Linköping University, Linköping, Sweden

Lisa Ferm, +46(0)13282143, lisa.ferm@liu.se Department of Behavioural Sciences and Learning, Linköping University, Linköping, Sweden

Daniel Persson Thunqvist, +46(0)13282061, daniel.persson.thunqvist@liu.se Department of Behavioural Sciences and Learning, and HELIX Competence Centre, Linköping University, Linköping, Sweden

Louise Svensson, +46(0)13282096, louise.svensson@liu.se Department of Behavioural Sciences and Learning, and HELIX Competence Centre, Linköping University, Linköping, Sweden

Maria Gustavsson, +46(0)13282558, maria.gustavsson@liu.se Department of Behavioural Sciences and Learning, and HELIX Competence Centre, Linköping University, Linköping, Sweden 


\title{
Students' strategies for learning identities as industrial workers in a Swedish upper secondary school VET programme
}

\author{
The aim of this article is to investigate the learning strategies vocational students \\ use to become part of a work community, and how these strategies are related to \\ the formation of a vocational identity at the workplace. Conducting qualitative \\ interviews, data were collected from 44 industrial programme students from six \\ upper secondary schools. The findings revealed five recurrent strategies used by \\ the students for learning vocational identities as industrial workers. The students \\ took individual responsibility for their own learning, asked questions to gain \\ deeper vocational knowledge, searched for role models in the work community, \\ positioned themselves as a resource to the work community, understood and used \\ humour and jokes in order to become a member of the community. The \\ conclusion is that the students actively develop learning strategies to adapt their \\ behaviour to the norms and ideals of the industrial work community. In the \\ process of develop the vocational identities as industrial workers, the students' \\ vocational habitus is transformed to better fit the industrial work community. The \\ integration of the notions of agency and habitus demonstrates the dynamic nature \\ of students' participation in work communities; simultaneously, the students \\ reproduce social structures that promote vocational identities.
}

Keywords: vocational learning, apprenticeship, vocational identity, VET, students' strategies, vocational habitus

\section{Introduction}

This article focuses on the strategies students use for learning vocational identities as industrial workers during their workplace-based learning in an upper secondary school vocational education and training (VET) programme. Internationally, Swedish VET is primarily associated with the Nordic model of education, circumscribed by universalist welfare states and well-regulated labour markets. In comparative VET literature, 
Swedish VET is considered to be primary model of school-based VET as it is an integral part of a state-governed, publicly funded and comprehensive school (Dobbins and Busemeyer 2014). In addition, over time the major labour market organisations and export industries have supported a generalist character of VET in line with their demand for a well-educated workforce (Berner 2010). The main characteristics of VET programmes in upper secondary school are the combination of higher education preparatory studies that give all students formal access to further studies, and vocational training organised in classrooms and workshops in close interaction with vocational teachers representing different occupations. Although vocational education is oriented towards skilled employment, it has proved difficult to develop and maintain vocational identities among both students and teachers through school-based education only (Jørgensen 2015).

In an attempt to handle a dual problem of high youth unemployment and shortages of skilled labour in the industry sector, workplace-based learning has recently gained a more prominent role in Swedish upper secondary school VET (Persson Thunqvist 2015). Workplace-based learning in upper secondary school presents an interesting and timely case because of the current prominence in the Swedish government's strategy to improve the ties between school and work, and strengthen young people's direct access to the labour market. Another goal is to use different forms of apprenticeship as a social-political measure to battle social marginalisation among school-weary young people. What makes the topic regarding vocational learning even more relevant is that the role and meaning of workplace-based learning is rarely examined among young people in the context of universalist school-based VET systems. As previous research has shown, the workplace is an important locus of 
learning and identity formation for young people in their transition from school to work (e.g. Berner2010; Jørgensen 2013; Tanggaard 2007).

In addition, workplace-based learning is pivotal in learning a vocation in its natural environment (Billett 2014a; Lave and Wenger 1991; Rausch 2013) and for developing a vocational identity (Klotz, Billett and Winther 2014), as it provides students with in-depth vocational knowledge and rich opportunities to use their skills learned at school in a workplace context. Workplace-based learning has also been shown to influence students' identification with a particular vocation, as it facilitates socialisation to work (Jørgensen 2013), and affects students’ self-confidence as well as their sense of self (Brockmann 2013; Chan 2013; Jørgensen 2013). Using Lave and Wenger's (1991) terms, the students are formed into new people by becoming part of a community of practice and by moving toward an identity as a skilled practitioner. As noted by Evans et al. (2010), at the centre of the process of learning and becoming are the strategies that the students use:

to bring together knowledge gained through the programme gleaned from working with more experienced people in the workplace. These strategies sometimes involve learners in the creation of new knowledge, insights and activities (Evans et al. 2010, 247).

As suggested by Evans et al. (2010), the strategies that students use for learning a vocation are developed by connecting knowledge acquired in the VET programme with knowledge gained by working in the workplace. As workplace-based learning is quite different to school-organised training, we can expect that the students have to change their learning strategies as they adapt to new circumstances in the workplace. The examination of strategies can deepen our understanding of the students' role as actors (active agents) in the process of learning a vocation and transforming their identities by becoming part of a work community (Evans et al. 2010). 


\section{However, several researchers have described students' difficulties navigating}

between the two systems the school and the workplace (e.g. Jørgensen 2013;

Persson Thunqvist and Axelsson 2011; Schaap, Baartman and de Bruijn 2012).

The school system is based on educational norms and is student-centred while the workplace is affected by corporate rationalities and emphasises adultness (Berner 2010). School and work constitute different types of learning experiences for students (Berner 2010) and represent diverse forms of vocational knowledge (Akkerman and Bakker 2012). Handling the hybridity of school and workplace-based learning is not merely about developing strategies for dealing with differences; it also has to do with creating a connection between what happens in school and at the workplace (Akkerman and Bakker 2012). Vocational education results in students negotiating their participation in different ways by making compromises and transforming their roles and identities (Persson Thunqvist and Axelsson 2011). Vocational education offers opportunities for workplace learning and prepares students for the development of vocational identities (Jørgensen 2015). Vocational education provides youths that do not fit into the regular school system and that are alien to an academic curriculum with an alternative pathway to a vocation and the labour market (Polesel and Clarke 2011). While previous research (e.g. Berner 2010; Akkerman and Bakker 2012; Persson Thunqvist and Axelsson 2011) has demonstrated how students' participation in school situated VET is fraught with tensions originating from the different logics of the school world and working life, the main contribution of this article is to gain more empirical knowledge about the learning strategies that students use when they enter the workplace setting.

The aim of this article is twofold: 1 ) to investigate the learning strategies that vocational students use to become part of a work community, and 2) to analyse how these strategies are related to the formation of a vocational identity at the workplace. 
The empirical material is based on interviews with 44 industrial programme students from six different Swedish upper secondary schools.

In the following section, the article starts by outlining the theoretical framework, which encompasses a workplace perspective on students’ strategies for vocational learning as well as theories on vocational learning and vocational identity. The subsequent two sections provide an overview of the research setting. Thereafter, the findings are presented; they show that the students used a set of recurrent learning strategies that cut across different workplace settings. Finally, the findings are discussed and conclusions are presented.

\section{Theoretical framework}

In the analysis, the focus is particularly on students' strategies and their experiences of participation in work communities - strategies and experiences that tie into notions about vocational learning and vocational identities. Vocational learning is conceptualised as being the consequence of participation in social practice through engagement in workplace activities, and access to support and guidance, implicating a social-practice perspective on learning (Billett 2011). The key to vocational learning lies in being granted access to participation in a community of practice (Lave and Wenger 1991; Wenger 1998). A community of practice can be understood as a social arena whose members share a common activity. Gradually, the increasing access to participation grants the novices the role of equal and full participant. The learning process is described as a shift from legitimate peripheral participation to full participation in a community of practice (Lave and Wenger 1991). According to Wenger (1998), the notion of participation is not restricted to specific activities. It also has to do with a sense of belonging to a community of practice. As noted by Akkerman and Bakker (2012), vocational students first have the roles of peripheral participants in 
the community of practice. However, Fuller (2007) criticises that the hierarchical dimension is not considered in the debate about the workplace as a community of practice, which means that social, political and economic conditions that shape the workplace-learning environment are not examined. Diverse conditions in the workplace may influence to which extent individuals and groups of workers have rich or poor access to learning opportunities. As Fuller and Unwin (2003) argue, supportive learning environments are essential for accessing an increasing degree of participation in the community of practice. Gradually, the students' participation is shaped by different conditions and support in the workplace and by the students' personal engagement (Evans et al 2010; Yuen Sze Goh and Zukas 2016) and, the level of the learner's engagement is partly connected to the identity (Billett and Somerville 2004). Armishaw $(2007,1)$ defines a vocational identity as a 'work identity that reflects a determination on the employee's part to commit to the values of the work group'. It is clear that this definition contains an important social aspect that relates to becoming an integrated member of the work group. This aspect has to do with commitment (Armishaw 2007) and adoption of behaviour specific to a particular profession (Chan 2014) or vocation (Billett 2011). According to Billett (2011), the term vocation is more related to personal engagement than the term occupation, which refers more to specific activities.

In the field of vocational learning and vocational identity, different strategies for learning and developing a vocational identity can be identified. The notion of learning as participation includes aspects that may be understood as strategies for learning a vocation, such as learning through everyday work, paying attention to what happens in the workplace and having others demonstrate tasks (Felstead et al. 2005). Students' engagement combined with invitations by others to participate in various activities is also essential for vocational learning (Billett 2001), and the sharing of the informal rules 
of a specific workplace can shape the vocational identity (Chan 2014). Learning the informal social rules of the workplace may also be viewed as a vocational learning strategy. For example, learning how to talk and use in-group humour is a way of moving closer to a core membership in the community of practice (Holmes and Woodhams 2013).

Apprenticeship has been identified as an important strategy for strengthening the confidence in the learning process and the vocational identity (Brockmann 2013). By learning a vocation, the apprentices achieve self-validation and gain acceptance from society. The journey of apprenticeship constitutes much more than an opportunity to learn an occupation; it also includes the important aspects of feeling, thinking and acting like a professional (Chan 2014) and prepares students for a life beyond work (Chan 2013). As noted by Akkerman and Bakker (2012), vocational students are expected to show a deeper knowledge of the work - knowledge that extends beyond knowing how things are done; they need to understand why things are done in a specific way. Taylor (2009) argues that among employers, personality and attitude are often more valued than concrete and technical skills. Responsibility can be seen as an important part of this attitude. If apprentices are entrusted with much responsibility, their engagement and self-esteem increase and they come to feel that their actions have an influence on the workplace (Reegård 2015).

While Billett (2014 b) highlights the importance of individual engagement for learning and developing a vocational identity, he also reminds us that this process of learning takes place in a social environment whose norms affect the learners. The strategies that students use for learning and developing a vocational identity are influenced by the status of the vocational education and how a particular occupation is viewed by society, and social barriers, such as class and gender (Billett 2014 b). Billett 
(2014 a, 466) emphasises that learning is formed by 'our socially shaped personal histories'. Billett's way of reasoning has similarities with Bourdieu's (1977) concept of habitus. Bourdieu argues that social structures are internalised and that the individual's social background and predispositions, such as social class and gender, affect the current behaviour, which in turn shapes the individual's sense of self (Bourdieu 1977; Lehmann and Taylor 2015). For instance, Sawchuck (2003) argues that social class can influence individuals' access to a community of practice. Therefore, we assume that social class can also influence the learning strategies used for developing a vocational identity. Following Bourdieu’s concept of habitus, Colley et al. (2003) develops the concept of vocational habitus, which refers to a process that orientates students’ learning to a particular identity. According to Colley et al. (2003, 488) orientating to a particular vocational habitus can be described as becoming "the right person for the job”. By using the concept of vocational habitus, Colley et al. (2003) suggest that the orientation process includes adopting desirable vocational behaviours and attitudes as well as looking, feeling and acting in conformity with the intended vocation. As is argued in this article, increasing degrees of participation in different activities in the everyday work, and the learning strategies that students use are important for becoming a member of a work community and for forming a vocational identity.

\section{Research setting}

The students in the study came from six different upper secondary schools and were all enrolled in the industrial programme. The industrial programme is one of twelve Swedish upper secondary school VET programmes. As noted by Berner (2010), the industrial programme has a relatively low status, and therefore, it attracts many schoolweary students with low motivation. Commonly, this student group (mostly boys with 
working-class background) is described as having poor grades and difficulties to adapt to the school system (Berner 2010). In four of the participating schools, the industrial programme was given as a school-located VET-programme, and in the other two schools the programme was organised as an upper secondary school apprenticeship. The two educational models have identical courses and intended learning outcomes, and lead to the same vocational qualification. Students with such a qualification can work in a diverse range of occupations in the industrial sector. Further, both models emphasise that the workplace-based learning included in the programme is essential in learning the vocation. The only difference between the two educational models is that in the upper secondary school apprenticeship model, formally, 50 per cent of the three-year programme is dedicated to workplace-based learning. The corresponding figure for the school-based VET model is a minimum of 15 weeks. Formally, the amount of time for workplace-based learning seem very different in the two models, but in practice, each of the schools have considerable leeway in determining the amount of time students spend on workplace-based learning. In the schools studied, the regulation of fifteen weeks was interpreted widely and varied between less than fifteen weeks and up to one year. However, the time spent by the students on workplace-based learning did not seem to influence the learning strategies they used.

In Sweden, school-located VET has a long tradition. In the $1970^{\mathrm{s}}$, initial vocational education became part of the Swedish school system. Before this, vocational learning was left to the different vocations. In 2011, an educational reform introduced upper secondary school apprenticeship as an alternative to the school-based VET. The political agenda behind this reform suggested apprenticeship in upper secondary school as a possible solution to high school dropouts and unemployment. Moreover, the assumption was that upper secondary school apprenticeship could provide a work force 
suited for the needs of the labour market. However, in spite of this reform, today apprenticeship is still a peripheral part of the Swedish upper secondary school system (Andersson, Wärvik and Thång 2015).

A great deal of the responsibility for school-located VET as well as upper secondary school apprenticeship rests on the schools; the workplace representatives have a much weaker position than in other Nordic countries. Contrary to their Danish and Norwegian counterparts, the Swedish employers lack influence over the vocational exams. Hence, a strong division between school and work characterises the Swedish school system (Andersson, Wärvik and Thång 2015). In the Swedish upper secondary school VET-programmes, the youths are both apprentices and students simultaneously. In the Swedish upper secondary school system, the companies at which the students undertake their workplace-based learning are required to support the students, who are entitled to a formal supervisor responsible for the students' learning and training at the company. Hence, the students are not supposed to manage on their own during the workplace-based learning.

\section{Method}

The material consists of 40 semi-structured interviews with 44 students (33 boys and 11 girls) aged 18 to 20 years, from six different schools. On the request of a few students, four interviews were conducted in pairs. Eight of the students were on their second year and the other 36 students on their third and final year of the programme. Thirty-five of the students were enrolled in school-located VET programmes, whereas the remaining nine students were enrolled in upper secondary school apprenticeship programmes. In this study, the students are not separated based on the type of programme, as there are more similarities than differences between the students’ learning strategies. 
The schools and students were strategically selected. The criterion for contacting the schools was that they offered the industrial programme. The principals responsible for the industrial programme in each school received written information about the research project. The principals who agreed to participate forwarded the information about the study to the students in the industrial programme. The students voluntarily participated in the interviews and were reassured that they had the right to discontinue their participation at any time.

The students selected all had experience from workplace-based learning in different types of industrial work. The students carried out their workplace-based learning in process industries and manufacturing companies of varying size, from a few employees in family companies to multinational companies with several hundred employees. In the companies, the students were offered to learn qualified industrial work in the area of welding work, machine maintenance work, assembly work, and pulp and paper production work.

Three of the authors of this paper conducted the interviews at the students' respective schools. On average, the interviews lasted 60 minutes. The purpose of the interviews was to capture the students' experiences of their workplace-based learning in the industrial programme. The focus was on questions regarding their strategies for learning vocational identities during the workplace-based learning. Not all the data from the interviews are presented in this article. The interview material is part of a larger research project about workplace-based training and the conditions for learning vocational identities in industrial work.

\section{Data analysis}

The interviews were transcribed in verbatim. In the initial analysis, all transcripts were read for familiarisation and to gain a broader understanding of the interview extracts. 
Notes about themes in the interviews were taken for further analysis, and joint analytical discussions were carried out in the research team. In the next step, a qualitative content analysis was carried out, resulting in categorisation of different themes that connected to various aspects of the students' learning and identity formation. During the course of the analysis, a set of recurrent strategies (indicating collective patterns) that cut across different workplace settings was identified. The material was again screened for these learning strategies and examples were collected from the interview transcripts. In this part of the analysis, the analysis was guided by the theoretical assumption about students strategies developed by Evans et al. (2010), including notions of vocational learning and vocational identity formation (Billett 2011). Using these concepts in the analysis was helpful in order to further examine the multifaceted ways in which the students interconnected knowledge from school and work during their workplace-based learning in different industrial companies.

\section{Findings}

When the students entered the workplace-based learning during their final year, they had acquired considerable industrial skills in school workshops and classrooms, and they had started to develop a vocational identity in connection to a specialised vocation. The interviews revealed differences among the students concerning their experiences and motivation for the workplace-based. For students who had managed quite well in school, workplace-based learning represented opportunities to put their vocational knowledge in use and further develop their vocational identities. For other more schoolweary students articulated that their main motivation for workplace-based learning was the prospect of leaving school quite soon for an employment in the industry. Besides such differences, workplace-based learning comprised a new challenge for the students' participation in work, significantly out of step with how they had participated in 
classrooms and workshops. In the following section, the focus is on the learning strategies that the students utilised during their workplace-based learning to become part of the industrial work community.

\section{Taking individual responsibility}

One strategy for learning and developing an identity as an industrial worker was to take individual responsibility for gaining access to learning opportunities during the workplace-based learning. The students said that it was their own responsibility to participate in tasks and events that could help them learn the vocation.

They put a lot of responsibility on me and this makes me feel very involved- you get an assignment that you're supposed to do and you're left alone with it, then, well, they just expect it to be done. There's no special treatment or anything like that, you get to do everything that the others do.

The students described that it was up to them to act on opportunities to develop their skills. The mantra that the students repeated was 'It's up to you'.

I feel that now we are actually young adults and you actually have to, it's about personal responsibility you know, it is what you make of it.

The students perceived that their own personality and effort were very important in gaining access to different tasks. Therefore, the students did not seem to hold the school personnel, such as the head teacher and teachers, responsible for providing support during the workplace-based learning. As the students thought that it was their own responsibility to learn, very little pressure was placed on the workplace to create a supportive and pedagogical environment for the students.

Researcher: Okay, okay so it’s about you not really knowing what tasks you were supposed to do? 
Student: No, and I tried to be...helpful and productive in the workshop, to go around and ask the different workers if they needed help (...)

The students had figured out school's rationale; it wanted to pair the 'best' workplaces with the most well-behaved students. The students described that their willingness to take responsibility was a strategic choice made not only in order to learn the vocation, but also to increase their possibilities of obtaining employment on a strained labour market.

It depends on your attitude, how willing you are to get a job (...) A lot of people say that there aren’t any jobs but if you try hard enough you can get a job.

The students perceived that their responsibilities also included judging what tasks they should avoid in the company. The students shunned work tasks that they were not sure how to perform and tasks that they had not yet learned in school. They also avoided tasks for which they lacked a licence, such as forklift driving and welding. Other tasks were dismissed as too difficult to perform. Yet other tasks were avoided because the students were afraid to make mistakes that could cause high expenses for the companies. On the other hand, there were tasks that the students were not allowed to perform. The students said that they understood very well that they could not participate in such tasks, since any mistakes made were associated with large economic risks for the companies. The students' sense of responsibility even stretched as far as the workplaces’ economy and efficiency.

\section{Asking questions}

A frequent learning strategy used by the students in order to gain deeper vocational knowledge was to ask questions. The students expressed a recurrent wish to understand the work process and production chain. The acquisition of vocational knowledge, i.e. 
knowledge about what they were doing, and the fact that they gained an overview of the whole production process facilitated the students' learning of the vocation. The students were eager to learn how to operate machines and apply different working methods in order to understand why things were done.

I ask a lot of questions because I want to know exactly what we are doing, what kind of machine it is (...) And then of course I ask questions like 'What are we going to do and what parts are we going to replace? What does this machine do when it's working? What is produced in it?' So I ask a lot of questions and we have discussions, it works fine.

The students appreciated receiving more thorough explanations of work processes compared to just receiving concrete directions about a detached task. The students said that asking questions, and thereby showing engagement, was a strategy they used to gain deeper vocational knowledge. Moreover, they recognised that the attitude conveyed by asking questions was appreciated by their employer and co-workers.

I mean, they (others at the workplace) take into consideration that you're new and that you don't know it all yet and that you need to ask a lot of questions. It's better to ask than to stand around doing nothing and appear stupid because you don’t understand. They say: better to say that you don't know than to just pretend to know it all, and then make mistakes. They say that very often.

Although the students were aware of the need to ask questions in order to acquire deeper vocational knowledge, they were afraid to disappoint their co-workers by appearing incompetent. It was hard for the students not to appear incompetent when trying to ask the right kind of questions so as to show an interest in the vocation.

Student: (...) well, I've always been kind of like 'I don't want to ask for help, I'll try myself'. But then I realise that 'I have to ask for help.' Otherwise, I can’t carry on.

Researcher: What is it that keeps you from asking for help? 
Student: Maybe I hope for too much....I think 'they think that I know more than I actually do’.

The findings indicate that the students faced somewhat of a dilemma. On the one hand, asking questions was crucial in learning a vocation, but on the other hand, when asking questions, the students ran the risk of being regarded as incompetent.

\section{Searching for acceptance and role models in the work community}

One important strategy for learning the vocation was to search for acceptance and role models. The students described that the more trust the co-workers and supervisors put in them, the more tasks they had access to.

In the beginning, it's kind of like you are an apprentice but then when you show your skills you start to become accepted as a member of the group

The students' commonly described their co-workers as nice and welcoming. 'I feel like I was part of their family so to speak'. Receiving acceptance in the group was easy for most of the students. The students thought that the co-workers on the shop floor had an important impact on their vocational learning. The students gained much vocational knowledge by watching and communicating with the more experienced workers. They perceived that the co-workers who were significant for their learning often explained tasks in a pedagogical way, increasing their understanding of the vocation of the industrial worker. The students admired their co-workers' vocational and pedagogical skills. The latter were useful not only in teaching the vocation, but also in showing the students how to behave at the workplace. All the students had a formal workplace supervisor, whose task was to support the students' learning. For some students, this person was a very important role model: 
For my part, I feel that I've learned a lot from my supervisor at the workplace. How to kind of behave at the workplace, and when you see him you learn a lot about how to treat other people. And then I like that he does it pretty well and you learn quite a lot from it.

Other students said that their regular supervisor was absent quit often. When the regular supervisor was absent, it was not uncommon that the students had access to an informal supervisor or mentor at the workplace.

Another guy that I viewed as my supervisor was (name). He was a welder that I spent a lot of time with. He gave me lots of tasks to do in the workshop (...) He and I keep in touch as well, kind of like friends. He skates so we had something to talk about, something in common, so he was like a supervisor to me.

The students said that it was easy to find role models in the companies. Most of the role models were co-workers with which the students worked closely. The students perceived that their vocational pride and self-esteem could be strengthened by the coworkers’ support and encouragement.

You feel so proud, if you can do it, because he (name) said that he couldn't even give the adult students as much work as he's given me, and then you feel really proud that you can stand there by the machine while he's taking a coffee break, well, then I operated both machines at the same time, that's no problem because I could handle it. That was a great feeling. Then you know that you're really able to do it. So it's nice to get to hear that and to receive some feedback.

As the quote indicates, the role models helped improve the students' confidence by allowing them to operate the machines by themselves. 


\section{Positioning oneself as a resource}

The students positioning themselves favourably in relation to the normative and sanctioned ways of acting, talking and behaving in the workplace seemed to be a major strategy for learning how to become an industrial worker.

And then you get to hear what the companies want, you know what kind of people they want, it's about the same at all companies, you have to be on time, get involved, not just hang around, you have to kind of always be in great form and be alert and everything. And you get to hear that, and then you know how to behave. So that's really good to know.

The students put a lot of emphasis on the importance of behaving well, which in this context meant to be on time, ignore your mobile phone and be nice to other co-workers. Having an attitude appropriate for the vocation and behaving in a pleasant way were seen as very important for the learning, the development of the vocational identity and the chances of obtaining employment after graduation.

If you show who you are and that you are competent and things like that, that you're always on time and that you do everything that you are supposed to do then you have a higher status than the others (...) you advance through the ranks, so to speak.

Here is another example of two students discussing their future job opportunities:

Student 1: I think the best attitude one can have is to really step into the spotlight kind of show yourself off.

Student 2: You have to stay on your toes all the time.

Student 1: Exactly, you have to be alert.

(...)

Student 1: Even if you get the dirty work you shouldn’t you know: ‘No, but I don’t want to', you know. It's better to do it, put your best foot forward, show that you're committed.

Student 2: Yes, that way they entrust you with more and more tasks, they trust you better. It's about kind of showing them what you're worth. 
The students expressed a high awareness of the advantages gained by behaving well. Most of the students made great efforts to conform to the companies' behavioural norms, since they realised that if they positioned themselves as a resource, they could achieve a higher status in the work community. Concurrently, there was also a high awareness among the students that their co-workers in the company may view them as burden. The desire to be seen as a resource rather than a burden at the workplace was expressed in different ways by the students.

\footnotetext{
(...) otherwise it's just having an apprentice that's just running around asking questions all the time or playing with her/his cell phone, so it’s just a burden for them to have me there if it were like that, but they were pleased with me (...).
}

Then they can give you tasks and then it's kind of fun, when they kind of let you handle tasks on your own... so you feel that you're contributing, that you're being there is not just a burden.

The students tried to position themselves as a resource in order to gain access to the work community. By behaving properly and showing a positive attitude, they created learning opportunities at the workplace.

\section{Understanding and using jargon}

The students perceived that being accepted as a team member had a lot to do with your attitude towards jokes. The students said that an important strategy for becoming an industrial worker was to present oneself as a relaxed and insensitive person who can take jokes and talk in the workplace jargon. Jokes and discussions about non-workrelated subjects were seen as signs of inclusion and proof of acceptance in the work community - even as a rite of passage. 
I really enjoyed being there (...) they knew that they could joke with me and I could joke with them (...) nobody took offence (...)

According to the students, a relaxed atmosphere in the workplace could indicate that it was a good time to tell a joke. Some of the students experienced that apprentices were more subjected to jokes than the rest of the co-workers, while others stressed that they were treated equally in this respect.

If you are to work in such workshops you have to be able to take some jokes, you can't take everything seriously, because (...) they joke around with each other and it's not...always the nicest types of jokes but well you just have to get back at them.

The students were of the opinion that sensitive people who are offended by strong language and insensitive jokes are not suited for industrial work. Nonetheless, the students agreed that there were no bad intentions behind the jokes and some students meant that this was a part of the apprenticeship that you had to accept. The students described that the jokes were about their lack of knowledge of tools or their being blamed if something went wrong.

If they say the name of a tool and I don't know what that is, they laugh a little and joke about it, kind of like 'oh ha ha', I can take that. But then, as I said, there are people who can’t take it, maybe they feel hurt or something like that. I thought it was funny but sometimes it could go a bit too far. (...) it got a little awkward. But well, it was nothing... you had to remember that you are an apprentice, so you have to be able to take some crap.

The students interpreted some of the jokes as sexist, racist or 'not the nicest kind of jokes', but they still did not question the good intentions behind them; 'they mean no harm'. A student said that he was subjected to even more jokes than other co-workers since he was going to be employed after his workplace-based learning. A female 
student, for whom it was difficult to gain acceptance from the men at the workplace, described how she finally got these men to greet her by smiling a lot, trying to make them laugh and letting go of the 'stiff feeling'. Thus, handling the jargon was a learning strategy used for showing that you were fit to work in the industry.

\section{Discussion}

The findings demonstrate a pattern of recurrent learning strategies used by the students, which helped them gain knowledge from working with experienced co-workers in the workplaces (Evans et al 2010). These were adaptive learning strategies used to learn company-specific norms, cultural values and identify role models. Thus, the students' vocational identity developed in response to the learning strategies they used and the learning opportunities that they encountered during their workplace-based learning. Furthermore, the students in this study appeared surprisingly more active and motivated to learn than previous research has shown (Jørgensen 2015; Willis 1977). As noted by Jørgensen (2015), a counter culture can emerge in contrast to classroom ideals while the workplace-based parts of the schoolwork are highly valued.

In order to become members of the work community the students took individual responsibility, asked questions, searched for role models, positioned themselves as a resource and used jargon. These strategies were intrinsically intertwined with the development of the students' vocational identities as industrial workers. These learning strategies were seemingly the key for the students in gaining access to the community of practice (Wenger 1998) and as they moved closer into the community of practice, in the formation of their vocational identities as industrial workers. The students’ learning strategies and development of a vocational identity was strongly related to the work community's values (Armishaw 2007) and adaption to the desired 
and expected vocational behaviour (Billett 2011) within the community of practice (Wenger 1998).

The students' 'it's up to you' mind set revolved around the strategy of taking individual responsibility for obtaining access to tasks and events that could assist in learning the vocation. The importance of the students' personal agency is evidenced by their way of speaking about their individual responsibility (Evans 2007). The students were well aware that the choice of learning strategies could have a significant impact on their becoming an industrial worker, and consequently, they accepted a great amount of individual responsibility for their vocational learning, almost to the extent that their schools were freed from some of their responsibility. In this regard, the findings indicate that the pedagogical arrangement between the schools and the workplaces does not fully succeed in meeting the demands of the industrial programme’s curriculum. In the Swedish upper secondary school system, the school and workplace are jointly responsible for the planning of the students' training at the workplace, and consequently, for monitoring the students’ knowledge development (Andersson, Wärvik and Thång 2015). Formally, during the workplace-based learning, the students should be offered versatile training and be supported by a supervisor in order to achieve the intended learning outcome of the upper secondary school curriculum. Thus, the workplace is expected to function both as an authentic production environment and a pedagogical setting. The students’ engagement was essential for fulfilling the workplace-based learning related requirements of the curriculum (Billett 2001; Chan 2014). However, the students’ engagement was necessary, but not enough. As previous research has shown, important conditions for workplace-based learning, as well as for the expansiveness of the workplace, are related to the pedagogical and institutional 
arrangement through which the students can be supported in order to access vocational knowledge (Evans et al. 2010; Fuller and Unwin 2003).

Asking questions was a strategy for gaining deeper vocational knowledge. The students aspired to know more about the vocation than simply how something was done (Akkerman and Bakker 2012). Trying to find out why things were done in a particular way, the students began to feel and think like industrial workers and became prepared for working in the in the industrial sector (Chan 2013). The wrong kind of questions could, however, undermine the image of the students as competent workers.

Another at least as important learning strategy was to search for role models. The right role model could create valuable learning opportunities, giving the student the chance to work with more experienced co-workers. Co-workers with good vocational skills and teaching abilities were appreciated. The students' self-confidence and selfesteem were strengthened when they were entrusted with tasks and use machines by themselves (Brockmann 2013; Chan 2013). Cooperating with others and taking individual responsibility, the students adapted to the norms and ideals of the vocation. The students recognised that the employers tended to value the right attitude over concrete skills (Taylor 2009; Reegård 2015) and that social skills were more highly valued than purely rational and technical knowledge (Nielsen and Tanggaard Pedersen 2011).

The students did not only search for role models. An equally important learning strategy was to position oneself as a resource. If the students had the right attitude and were not seen as a burden by their co-workers, they could rapidly move from a peripheral role to a more favourable position in the community of practice (Akkerman and Bakker 2012; Wenger 1998). As active members of the work community, the students had to prove that they were able to handle the informal jargon and jokes at the 
workplaces. Like 'the lads' in Willis (1977) study the students in our study attributed much importance to humour and laughter. Sensitive people who could not tolerate jokes were considered not to be fit for the vocation. A habitus (Bourdieu, 1977) or personal history (Billett 2014) that was in line with the jargon of the vocation facilitated the students' transition into the work community.

The findings also suggest that gender as a structural predisposition, produced different patterns of participation for the female and male students respectively. At the workplaces, there were norms and social barriers that affected the female students' learning strategies and formation of a vocational identity (Billett 2014b). The female students were seen as unsuited for working in the male-dominated industrial sector. The highly gendered industrial work itself seemed to act as a social barrier (Gustavsson and Fogelberg Ericsson 2010), which the female students had to handle and overcome before entering the vocation.

The attitude encouraged at the workplaces, the students' emphasis on taking responsibility and expressing interest, and the students' attempt to portray themselves as competent workers who can understand and use the workplace jargon can be seen as internalisation of the companies' rationality, a process of learning and becoming in which the students orientate to the habitus of the vocation (Colley et al. 2003). As the students learned the culture of the work community, they developed a vocational habitus in line with that of the industrial worker. However, the prior possession of a vocational habitus in line with the norms of the industrial work community benefited the students in the process of becoming industrial workers (Lehmann and Taylor 2015). Therefore, the vocational habitus could be seen both as a learning outcome and as a precondition for learning and forming vocational identities as industrial workers. 


\section{Conclusions}

In conclusion, the students' learning strategies offered a way of understanding how the students’ vocational identities as industrial workers were formed during their workplace-based learning. The students were aware of the ideals and rationalities of the vocation and through actively developing strategies for behaving and acting they adopted the right vocational identities. While adapting to the roles of young adults and employees, rather than the role of young, dependent students, the youths functioned as agents at the workplaces. In the process of vocational learning, they formed their vocational identities through adapting their vocational habitus to the ideals of industrial work. The 'right' vocational habitus could lead to a job in the company. Apparently, the workplace-based learning was quite demanding, because it could offer alternative learning careers and attractive vocational identities both during and after the vocational education.

The implications of the findings of this study, demonstrating students' active learning strategies to become skilled industrial workers, can also be framed in the context of an increasing political concern in improving the esteem of VET in relation to academic studies in many countries (Jørgensen 2015). In universal school-based VETsystems, apprenticeship and workplace-based learning is increasingly used as a socialpolitical measure to include school-weary young people in upper secondary education (Virolainen and Persson Thunqvist 2017) and to combat dropouts and social problems as well as a labour market policy measure, which may influence the forming of the learning environments in workplaces (Fuller 2007). It should be underlined that we only studied students who participated in workplace-based learning and they represent a selected group. For natural reasons, this group does not include those students that dropped out from the programme during the first or second year. This indicates that 
students that complete a programme and participate in workplace-based learning are those who have been able to develop identities in accordance with the vocational identities offered in the industry programme. However, more research is needed to see if the dropouts' learning strategies differ from students who succeed in VET. Another limitation in the study is that gender issues are not considered to a greater extent. However, there were signs of gender differences in the learning strategies that the students used when they entered the workplaces. Consequently, a question for further research is to analyse the pervasiveness of gender in students' learning strategies to develop vocational identities in the male-dominated industry. 


\section{References}

Andersson, Ingela, Gunbritt Wärvik, and Per-Olof Thång. 2015. “Formations of apprenticeships in the Swedish education system: Different stakeholder perspectives.” International Journal for Research in Vocational Education and Training 2: 1-24.

Akkerman Sanne F, and Arthur Bakker. 2012.“Crossing Boundaries Between School and Work During Apprenticeship.” Vocations and Learning 5(2): 153-173.

Armishaw, David. 2007.“ Vocational Identity: It’s About Working at Becoming.” College Quarterly 10 (2): 1-13.

Berner, Boel. 2010.“Crossing Boundaries and Maintaining Differences Between School and Industry: Forms of Boundary-work in Swedish Vocational School.” Journal of Education and Work 23 (1): 27-42.

Billett, Stephen. 2001.“Learning Through Work: Workplace Affordances and Individual Engagement.” Journal of Workplace Learning13 (5): 209-214.

Billett, Stephen. 2011. Vocational Education: Purposes, Traditions and Prospects. Dordrecht: Springer.

Billett, Stephen. 2014a.“Mimesis: Learning Through Everyday Activities and Interactions at Work.” Human Resource Development Review 13 (4): 462-482.

Billett, Stephen. 2014b. “The Standing of Vocational Education: Sources of its Societal Esteem and Implications for its Enactment.” Journal of Vocational Education \& Training 66 (1): 1-21.

Billett, Stephen, and Margaret Somerville. 2004. “Transformations at Work: Identity and Learning.” Studies in Continuing Education 26 (2): 309-326.

Bourdieu, Pierre. 1977.Outline of a Theory of Practice. New York: Cambridge University Press.

Brockmann, Michaela. 2013. "Learning Cultures in Retail: Apprenticeship, Identity and Emotional Work in England and Germany.” Journal of Education and Work 26 (4): 357-375.

Chan, Selena. 2014.“Crafting an Occupational Identity: Learning the Precepts of Craftsmanship Through Apprenticeship.” Vocations and Learning 7 (3): 313330.

Chan, Selena. 2013. "Learning Through Apprenticeship: Belonging to a Workplace, Becoming and Being.” Vocations and Learning 6 (3): 367-383. 
Colley, Helen, James David, Kim Diment, and Michael Tedder. 2003. “Learning as Becoming in Vocational Education and Training: Class, Gender and the Role of Vocational Habitus.” Journal of Vocational Education and Training 55 (4): 471498.

Evans, Karen. 2007. “Concepts of Bounded Agency in Education, Work, and the Personal Lives of Young Adults.” International Journal of Psychology 42 (2): 85-93.

Evans, Karen, David Guile, Judy Harris, and Helen Allan. 2010. "Putting Knowledge to Work: A New Approach.” Nurse Education Today 30 (3): 245-251.

Felstead, Alan, Alison Fuller, Lorna Unwin, David Ashton, Peter Butler, and Tracey Lee. 2005. “Surveying the Scene: Learning Metaphors, Survey Design and the Workplace Context.” Journal of Education and Work 18 (4): 359-383.

Fuller, Alison. 2007. “Critiquing theories of learning and communities of practice” In Jason Hughes, Nick Jewson and Lorna Unwin Communities of practice. Critical perspectives. London and New York: Routledge.

Fuller, Alison, and Lorna Unwin. 2003. ”Learning as Apprentices in the Contemporary UK Workplace: Creating and Managing Expansive and Restrictive Participation.” Journal of Education and Work 16 (4): 407-426.

Gustavsson, Maria, and Anna Fogelberg Ericsson. 2010. “Gendered Learning Environments in Managerial Work.” Studies in the Education of Adults 42 (2): 141-155.

Jørgensen, Christian Helms. 2013. "The Role and Meaning of Vocations in the Transition from Education to Work.” International Journal of Training Research 11 (2): 166-183

Jørgensen, Christian Helms. 2015. “Some Boys’ Problems in Education - What is the Role of VET?” Journal of Vocational Education and Training 67 (1): 62-77. Holmes, Janet, and Jay Woodhams, J. 2013. “Building Interaction: The Role of Talk in Joining a Community of Practice.” Discourse and Communication 7 (3): 275298.

Klotz, Viola Katharina, Stephen Billett and Esther Winter. 2014. "Promoting Workforce Excellence: Formation and Relevance of Vocational Identity for Vocational Educational Training.” Empirical Research in Vocational Education and Training 6 (6): 1-20. 
Lehmann, Wolfgang, and Alison Taylor. 2015. “On The Role of Habitus and Field in Apprenticeship.” Bourdieu and Work 29 (4): 607-623.

Lave, Jean, and Etienne Wenger. 1991. Situated Learning: Legitimate Peripheral Participation. Cambridge, MA: Cambridge University Press.

Nielsen, Klaus, and Lene Tanggaard Pedersen. 2011.“Apprenticeship Rehabilitated in a Postmodern World.” Journal of Vocational Education and Training 63 (4): 563573.

Persson Thunqvist, Daniel, and Bodil Axelsson. 2011. “’Now it's Not School, It's for Real': Negotiated Participation in Media Vocational Training.” Mind, culture and Activity 19 (1): 29-50.

Polesel, John, and Kira Clarke. 2011.“The marginalisation of VET in an Australian secondary school.” Journal of Vocational Education and Training 63 (4): 525538.

Rausch, Andreas. 2013. “Task Characteristics and Learning Potentials - Empirical Results of Three Diary Studies on Workplace Learning.” Vocations and Learning 6 (1): 55-79.

Reegård, Kaja. 2015.“Sales Assistants in the Making: Learning Through Responsibility” Vocations and Learning 8 (2): 117-133.

Sawchuck, Peter. 2003. Adult Learning and Technology in Working-class Life Cambridge: Cambridge University Press.

Schaap, Harmen, Liesbeth Baartman, and Elly de Bruijn, E. 2012.“Students’ Learning Processes During School-based Learning and Workplace Learning in Vocational Education: A Review.” Vocations and Learning 5 (2): 99-117.

Tanggaard, Lene. 2007. "Boundary Crossing between School and Work.” Journal of Education and Work 20 (5): 453-466.

Taylor, Alison. 2009. “Mapping The Field of VET Partnerships.” Vocations and Learning 2 (2): 127-151.

Virolainen, Maarit, and Daniel Persson Thunqvist. 2017. Varieties of universalism: post-1990s developments in the initial school-based model of VET in Finland and Sweden and implications for transitions to the world of work and higher education. Journal of Vocational Education and Training 69 (1): 47-63.

Wenger, Etienne. 1998.Communities of Practice. Learning, Meaning and Identity. Cambridge: Cambridge University Press. 
Willis, Paul. 1977. Learning to Labour. How Working Class Kids Get Working Class Jobs. Farnborough: Sanon House.

Yuen Sze Goh, Adeline, and Miriam Zukas. 2016. "Student Vocational Teachers: The Significance of Individual Positions in Workplace Learning.” Journal of Vocational Education and Training 68 (2): 263-277. 